\title{
O DESIGN DE LIVROS DE BOLSO: mediação entre sujeitos e objeto
}

\author{
Sibelle Carvalho de Medeiros \\ Pontifícia Universidade Católica do Rio de Janeiro \\ sibelle.cm@gmail.com \\ Jackeline Lima Farbiarz \\ Pontifícia Universidade Católica do Rio de Janeiro \\ jackeline@puc-rio.br
}

\begin{abstract}
Resumo: Este artigo parte de pesquisas realizadas sobre o objeto livro de bolso, considerados como objetos concretos capazes de construir significados próprios a seus leitores através das experiências - visuais, editoriais e comerciais- por ele proporcionadas. Embora, a primeira vista, tais publicações difiram unicamente das edições tradicionais pelo seu tamanho reduzido, é observado que as mesmas são elaboradas com um projeto gráfico-editorial distinto das demais. Além disso, entendendo que os aspectos materiais interferem na produção de sentidos da leitura os leitores de livros de bolso estabelecem maneiras distintas de se relacionarem e produzirem sentidos com eles. Neste sentido, é apresentada a noção de gênero, assim como o entendimento do Design como processo de comunicação e de linguagem. Finalmente, buscamos o entendimento do Design como campo mediador entre sujeitos e objetos, capaz de participar da ressifignicação dos diferentes processos de fruição de leitura.
\end{abstract}

Palavras chaves: leitura, produção de sentidos, mediação.

\begin{abstract}
This article is based on researches on pocket books as concrete objects capable of building meanings to its readers through visual, editorial and commercial experiences. Though, at first glance, such publications differ from the traditional editions only their smaller size, it is clearly noticeable that they are created using distinct graphic and editorial projects. Furthermore, considering that the material aspects interfere with the creation of meanings in reading, the readers of pocket books establish different ways of relating to and creating meanings with such books. In this sense the notion of gender is presented, as well the understanding of Design as a process of language and communication. Finally, we look for the understanding of Design as a neutral ground between subjects and objects capable of taking part in the resignifying of different processes of reading enjoyment.
\end{abstract}


Keywords: reading, creation of meanings, mediation

\section{INTRODUÇÃO}

Este artigo é parte de uma pesquisa de mestrado em Design desenvolvida atualmente, cujo recorte de estudo são as coleções de formato de bolso publicadas no cenário nacional em uma tentativa de compreender como este formato editorial potencializa determinados protocolos de leituras. Primeiramente, entendemos que os livros de bolso são caracterizados, principalmente, por possuir dimensões menores que os livros tradicionais e por seus valores relativamente mais baixos em relação aos demais. Laurence Hallewell (2005) afirma que o livro de bolso pode ser considerado como um conceito de marketing na medida em que seus custos não são reduzidos exclusivamente pelo seu tamanho, mas também pela sua grande tiragem. Essa característica possibilita a elaboração de um projeto gráfico diferenciado, o qual propicia que o leitor entenda tal publicação como um objeto diferenciado das edições tradicionais. Além disso, tal projeto gráfico não deve ocasionar dúvidas em relação a sua qualidade, assim como frustração das expectativas do leitor.

Buscamos o entendimento do que representa este projeto gráfico diferenciado, o qual possibilita o estabelecimento de novas relações entre leitor e texto. Desse modo, pretendemos aqui trabalhar com a noção de projeto-objeto-sujeito, percebendo o Design como elemento mediador dos protocolos de leitura dos livros de bolso. Também entendemos que é necessário que se trace um breve histórico dessas publicações no Brasil, objetivando conhecer o contexto de produção industrial que possibilitou a sua disseminação de obras com valor reduzido no cenário nacional.

Para o desenvolvimento deste artigo optamos por realizar uma pesquisa de caráter bibliográfico. Procuramos estabelecer relações entre o pensamento dos autores com o nosso objeto de estudo, atentando para os aspectos relacionados aos seus protocolos de leitura e a mediação entre sujeito e objeto. Para isso, percorremos as seguintes etapas:

Primeiramente, buscamos a conceituação mercadológica e editorial dos livros de bolso, para isso nos concentramos na análise desenvolvida por Laurence Hallewell (2005). Também nos preocupamos no estabelecimento do cenário histórico que permitiu a difusão de obras com preço reduzido no Brasil. Para isso, estudamos as obras de Rafael Cardoso $(2005,2009)$

Considerando que o entendimento dos hábitos de leitura vinculados aos diferentes suportes seria capaz de nortear a nossa questão de como ocorre o processo de diferenciação dos livros de bolso das demais publicações, nos enfocamos nos textos elaborados por Roger Chartier (2002).

Após isso, nos preocupamos no estabelecimento de como ocorre o processo de produção de sentidos na leitura de livros de bolso e como os aspectos pessoais influenciam este processo, para isso encontramos relevância no estudo de Jean-Marie Goulemot (1999).

Partindo da noção de os livros de bolso e suas características formais também são caracterizados por serem gêneros, nos enfocamos nos trabalhos de Bakhtin (1997, 2006) e de Marcuschi (2003). 
Por fim, buscamos estabelecer conceitos de design que atendessem a complexidade das relações interações estabelecidas entre sujeito e objeto. Encontramos fundamentação nesta etapa a partir de leituras baseadas na epistemologia do Design. Para isso utilizamos os textos elaborados por Sudjic (2010), Bonfim (1994), Flusser (2009) e Argan (1992, 2004).

\section{DESENVOLVIMENTO}

\subsection{A produção de Livros de Baixo custo no cenário nacional}

Com relação à disseminação da cultura escrita no cenário nacional, percebemos que enquanto a Europa vivia uma profunda transformação do hábito de leitura graças ao aumento da circulação de impressos e da ascensão do romance no século XVIII, o Brasil vivia sob domínio da coroa portuguesa. A inauguração oficial da imprensa no Brasil ocorre apenas em 1808, com a chegada da família real portuguesa e com a criação da Imprensa Régia.

Porém, segundo Rafael Cardoso (2005), a partir da década de 1840 e até 1890 ocorre novamente um processo decisivo na cultura escrita graças às mudanças tecnológicas ocorridas no período. Estas mudanças estavam relacionadas a fatores como: a difusão do papel fabricado a partir da utilização de polpa de madeira, ao uso da linotipia para a composição de textos, a mecanização das prensas tipográficas, a fusão mecânica de tipos e da difusão da litografia e da zincografia como técnicas de impressão de imagens e da eletrotipia.

Contudo, o autor (ibidem) alerta para a diferença entre a tradição de impressão manual, surgida após Guttenberg, e a indústria gráfica surgida no período entre 184050. Segundo ele, a industrialização dos processos gráficos esteve ligada a uma produção em grande escala. Além disso, a mecanização dos processos de impressão e de fabricação proporcionaram um elevado grau de padronização, gerando uma valorização da etapa de projeto. Ainda Segundo Cardoso (ibidem), tal acontecimento trata-se de uma regra na história do design gráfico, pois quando o impacto do trabalhador manual especializado - impressores, tipógrafos e compositores - é reduzido, ocorre uma elevação da importância das etapas de concepção e planejamento com a finalidade de garantir a qualidade final do produto. Desse modo, tal disseminação de matérias-primas com custos reduzidos e a presença de novos processos de impressão possibilitou um barateamento nos preços dos materiais impressos e um aumento significativo no número de leitores.

No que tange a produção de livros, Cardoso afirma (2009, p. 84) que a organização dos elementos gráficos dispostos nas páginas e nas capas permaneceu estável ao longo do século XIX e que o livro ainda era visto como objeto de luxo acessível a poucas camadas da sociedade, o qual necessitava de cuidados artesanais graças ao tipo de papel, encadernação e impressão. Assim, folhas de rosto representaram a maior área receptiva a grandes variações estilísticas da época. Com relação às capas, o autor também aponta que a ilustração começou a ser utilizada nesse período.

É, portanto, no período que compreende o início e o término da Primeira Guerra Mundial que o design de livros no Brasil teve sua ruptura mais significativa. Rafael Cardoso (2005, p. 176) aponta que nesta época houve uma difusão expressiva das edições de brochura com tamanho predominante de $18,5 \times 13 \mathrm{~cm}$, as quais necessitavam de um tratamento gráfico que as valorizassem em relação às edições 
tradicionais. É nessa conjuntura que a ilustração em capas de livros popularizou-se como linguagem voltada à comunicação visual.

\footnotetext{
Distanciando-se do tradicional culto ao livro como objeto de luxo, bem encadernado, com um bom papel e acabamento artesanal, as edições populares das décadas de 1910 e 1920 empreendem uma nítida tentativa de compensar com um projeto gráfico vistoso a má qualidade de seus materiais e seu péssimo acabamento (CARDOSO, 2005, p. 177).
}

Desse modo, é notável que as primeiras experiências em território nacional de produção de publicações consideradas "acessíveis" procuravam elaborar uma linguagem gráfica própria, de maneira que o produto final fosse concebido de maneira diferenciada em relação às demais publicações. Embora estas brochuras populares não fossem elaboradas como livros de bolso se faz importante refletir sobre suas características de modo a compreender as origens da concepção de livros com preço reduzido no Brasil.

\subsection{Design como mediador na produção de sentidos}

Atualmente, à produção de sentidos vinculados aos livros de bolso também participa dos processos de diferenciação desses objetos em relação aos demais. Roger Chartier (2002) alega que os fatores que proporcionam a leitura - como os sentidos de visão e de audição - são participantes ativos na construção de significados de uma obra escrita. Sendo assim, a atividade de leitura está intrinsecamente relacionada à maneira como seus dispositivos de escrita e comunicação estão disponibilizados ao leitor e a maneira como uma obra literária é organizada através de aspectos gráficos e visuais.

Destacamos também a existência de aspectos fisiológicos, históricos $e$ as bibliotecas pessoais, que conforme Jean- Marie Goulemot (1999) são elementos ativos na construção de sentidos na leitura. Para o autor, os aspectos fisiológicos estão relacionados ao modo de que o corpo do leitor se comporta ao ler um determinado texto. Assim, o corpo do leitor e a posição adotada ao ler um determinado texto ao mesmo tempo em que constituem uma livre escolha, simbolizam uma imposição já que revelam "atitudes-modelo" ou tipos de dispositivos biológicos adequados ao gênero do livro. Os aspectos históricos mencionados por Goulemot são relacionados ao modo como um texto é interpretado dentro de um contexto político e social. 0 autor também menciona a existência de uma biblioteca pessoal, onde as experiências vividas pelos leitores, a memória de leituras anteriores e dados culturais dialogam com o texto.

Embora o pensamento de Goulemot (1999) seja elaborado a partir de uma reflexão maior sobre as características do texto verbalizado, percebemos que é possível estabelecer paralelos com nosso objeto de estudo. Primeiramente, entendemos que os livros de bolso possuem uma fisiologia específica que auxilia na distinção dos demais livros, pois na medida em que estes objetos possuem um tamanho menor das edições tradicionais, a relação entre o corpo do leitor e o livro é estabelecida de modo distinto. Com relação aos aspectos históricos, podemos exemplificar através dos textos que são selecionados para serem publicados neste formato editorial e a maneira como os leitores interpretam seus conteúdos, pois refletem as escolhas politicas e os aspectos sociais dentro de um contexto de produção 
e circulação das obras. Finalmente, com relação à biblioteca pessoal é possível citar a existência de expectativas prévias por parte dos leitores acerca dos livros de bolso como, por exemplo, o seu baixo custo e seu descarte, o que a princípio já participa das possíveis produções de sentido a ele atreladas.

Convém afirmar, que o livro de bolso também possui características que o tornam semelhante aos textos difundidos nas telas de computadores e de e-readers e aos divulgados nos livros tradicionais, pois assim como esses, os livros de bolso também são configurados como gêneros do discurso. Neste sentido, Bakhtin (1997) colabora com a definição de gênero quando afirma que os gêneros são tipos relativamente estáveis de enunciados, marcados por sua infinitude e por heterogeneidade, ocorrendo quando qualquer atividade da língua é utilizada (seja verbal ou não verbal). O autor também afirma que os enunciados (ou também chamados de gêneros do discurso) são estabelecidos através de processos sociais e históricos, sendo, portanto, originário dos processos de interação entre sujeitos e meio social.

Em outro texto, Luiz Antônio Marcuschi (2003) afirma que os gêneros são textos materializados os quais contribuem para a ordenação e estabilização das atividades comunicativas diárias. Marcushi (ibdem) também salienta que últimos dois séculos as áreas da tecnologia, especialmente as ligadas à comunicação foram as responsáveis pela disseminação de novos gêneros textuais, que se relacionam com determinados gêneros pré-existentes, como no caso dos e-mails que tem como antecessor as cartas e os bilhetes pessoais, o que fortalece a ideia de que os gêneros são marcados por construções coletivas e interacionais ao longo da história. O autor contribui para a questão de que embora os gêneros não sejam definidos por seus aspectos estruturais e formais, muitas vezes o suporte auxilia na determinação de um determinado gênero, citando como exemplo um artigo cientifico publicado em uma revista cientifica e um artigo de divulgação científica publicado em um jornal diário, pois embora o texto divulgados nesses meios possa ser o mesmo, o suporte auxiliou no estabelecimento de hierarquia de valores, diferenciando assim os gêneros dos textos.

Logo, podemos afirmar que o gênero de um determinado objeto também é sugerido através da linguagem do design. Sudjic (2010) afirma que elementos como a cor, a forma, as referências visuais e o tamanho auxiliam nesse processo de definição do gênero de um objeto. $O$ autor também afirma que o design é o código que possibilita o entendimento da sociedade em que vivemos e uma espécie de reflexo dos sistemas econômicos, sociais e culturais. Para ele, o design é a linguagem que nossa sociedade utiliza para criar objetos que reflitam os seus objetivos e valores. Além disso, o autor atenta para a questão dos objetos terem significados além dos utilitários e cita o exemplo da tipologia de uma letra transmitir apelos emocionais. Para ele, o fato de uma letra ser chamada de "caractere" não é um fato a ser desconsiderado, pois a tipografia constitui-se como um elemento capaz de revelar a personalidade e o caráter humano de um determinado objeto.

O pensamento elaborado pelos autores acima citados auxilia ainda mais no estabelecimento da semelhança entre os livros de bolso e outros suportes de leitura. Primeiramente, o livro de bolso, objeto da pesquisa aqui realizada, apresenta paridades e disparidades com o livro tradicional. Assim como o último, por um lado, ele é um objeto impresso, o leitor, por exemplo, pode folheá-lo e realizar anotações de próprio punho, estabelecendo uma relação de pessoalidade, como no caso das 
dedicatórias. Por outro lado, seu formato particular desencadeia protocolos de leitura e produções de sentidos específicos de sua materialidade, como a facilidade de ser lido em locais de grande fluxo de movimentação, como no metrô, e de ser segurado por apenas uma das mãos, quando o número de páginas possibilita isso. Com relação aos textos divulgados nos dispositivos de leitura digital, percebe-se que embora a textualidade seja a mesma, seu gênero sofre modificações por estar inserido em um suporte de outra natureza, onde o texto tende a receber maior valorização que o objeto onde se realiza a leitura. É nesse mesmo, sentido que os livros de bolso podem estabelecer algumas semelhanças com o texto digital, pois não se percebe, a princípio, em ambos os casos um apego ao objeto e a sua materialidade. Além disso, ambos não são, na maioria das vezes, considerados como objetos agregadores de valores simbólicos, dignos de serem expostos em lugares destacados nas estantes de seus proprietários. A valorização destes suportes ocorre muito mais pelo texto que comportam, do que pela sua materialidade.

É nesse sentido, que passamos a considerar o Design como comunicação e como linguagem. Para Flusser (2009), a comunicação é estabelecida através de duas formas, a dialógica e a discursiva. O autor afirma que a comunicação dialógica ocorre quando os homens trocam diferentes informações na tentativa de criar uma nova informação através da sintetização do que foi dito. A discursiva ocorre quando existe o compartilhamento dessas informações na tentativa de prolongar o seu conteúdo perante a ação do tempo. No entanto, Flusser afirma que estes tipos de comunicação são inseparáveis, pois para a existência de um diálogo é necessária a disponibilidade de informações colhidas anteriormente graças à recepção de discursos anteriores. Além disso, cada diálogo pode ser considerado como uma série de discursos orientados para uma determinada troca, e cada discurso pode ser considerado como parte de um diálogo. A diferença entre estas esferas consiste, no entanto, na distância de observação.

Bomfim (1994) afirma que o Design é orientado por um conjunto de objetivos e interesses de instituições sociais. O Design, dentro deste cenário seria um instrumento para que a sociedade alcance a realização de suas utopias. Para o autor, as utopias apresentam dois significados distintos, primeiramente elas são o objetivo distante a ser alcançado (ideal), seguidamente são o anúncio do possível (real). Os produtos, independentemente de suas características particulares e únicas, são considerados para o autor como instrumentos para a realização de utopias, através das possibilidades de estabelecimento de relações dos sujeitos com outros sujeitos. 0 autor (ibdem) também apresenta uma breve definição de objeto configurado. Para ele, o que este objeto configura é a unidade entre forma, expressão da essência e conteúdo, essência do objeto ou o conjunto de elementos que definem a sua natureza.

Dentro desta mesma lógica, Flusser (2009) afirma que o design é uma ponte entre o mundo da arte e da técnica. Para o autor, o Design busca enganar a natureza através da utilização da técnica. Já o "objeto de uso", seria para Flusser (ibdem), algo que nós utilizamos para afastar um obstáculo do caminho. $O$ autor também atenta para a questão da "dialética interna da cultura", pois na medida em que criamos um objeto para vencer obstáculos, os mesmos tornam-se obstáculos posteriormente. Assim, na medida prosseguimos graças à construção de objetos para a solução de problemas existentes, notamos que o desenvolvimento dos mesmos é um processo sem finalização definida, dada a complexidade das relações sociais. Os objetos não 
são, portanto, apenas objetivos, mas sim um instrumento de mediação entre os homens.

É neste contexto de mediação entre sujeitos que encontramos relevância no pensamento cunhado por Argan (1992). Para ele, o objeto é tido como qualquer coisa que é definida, e ao mesmo tempo define um determinado sujeito. Assim para um objeto ser caracterizado como tal, é necessária a ação de um sujeito que o reconheça. Para o autor, existe uma tríade em nossa cultura marcada pela presença dos elementos projetoobjeto-sujeito.

Argan (ibdem) também afirma que um projeto é a relação direta estabelecida entre uma atividade intelectual e uma atividade manual. A cultura do projeto, segundo o autor, surge no século XVIII e foi antecedida por uma cultura voltada ao modelo. A diferença entre estes dois tipos de cultura consiste no fato de que o modelo requer uma atividade de reprodução e reflexão, enquanto que o projeto requer transgressão, a superação de si mesmo e a crítica do existente, visando alcançar algo novo e evidentemente melhor para a posteridade. $O$ autor também atenta para o fato de que todo projeto está ligado a uma noção de valor e alega a existência de uma crise na ideia de valor que afeta consequentemente ideia de projeto, pois é impossível conceber um projeto sem uma ideia de valor preexistente. Convém afirmar, que valor é uma atribuição de significado que damos as coisas e não é algo ligado a elas de maneira espontânea. Dessa maneira, o valor atribuído a uma determinada coisa é um fenômeno cultural. O projeto é, portanto, caracterizado por ser um procedimento e um processo de ações de valorização.

Assim, podemos retornar à questão da produção de sentidos nos livros de bolso. Ao entendermos o objeto em questão como fruto de uma mediação entre sujeitos, o qual carrega valores, percebemos que o design através da noção de projeto exerce um papel potencializador na produção de sentidos decorrentes ao ato da leitura dos livros de bolso.

\section{CONCLUSÃO}

Com as atuais possibilidades tecnológicas percebemos que os livros de bolso merecem uma revisão, no sentido do entendimento de seus lugares sociais. Tem-se em vista que eles sempre tiveram um local social diferenciado dos livros tradicionais e que foram projetados para uma sociedade com necessidades distintas da atual. Dessa maneira, entender as relações estabelecidas através de um determinado suporte, neste caso os livros de bolso, permite compreender não só o modo que os leitores o percebem - seus protocolos de leitura - como também e, principalmente, como o formato editorial influencia os hábitos de leitura e seus processos de fruição.

Consideramos também que o entendimento da relação entre projeto-objetosujeito e do design como comunicação e linguagem, permite ainda mais a compreensão da mediação entre texto, suporte e leitores. É necessário o entendimento não só sobre o modo que os leitores o percebem os livros de bolso, mas também da maneira como os projetamos. Só assim, conseguiremos uma ressignificação dos projetos e dos suportes na interação com a sociedade.

Por fim, entendemos que outras considerações serão possíveis com o andamento da atual pesquisa, principalmente através do contato com os leitores buscando o entendimento das maneiras como estes diferenciam e se relacionam com 
este formato editorial, contribuindo com o desenvolvimento de novos projetos gráficos e com diferentes atividades voltadas ao fomento da leitura.

\section{REFERÊNCIAS}

ARGAN, Giulio Carlo. A História na metodologia do projeto. In: Revista Caramelo, n.6. 1992- FLU-USP

BAKHTIN, Mikhail. Estética da Criação Verbal. São Paulo: Martins Fontes, 1997.

Marxismo e filosofia da linguagem: problemas fundamentais do método sociológico da linguagem. 12. ed. São Paulo: Hucitec, 2006

BOMFIM, Gustavo Amarante. Sobre a Possibilidade de uma Teoria do Design. In: Estudos em Design, v.2, n.2. nov.1994- Anais P\&D Design 94.

CARDOSO, Rafael. Impresso no Brasil, 1808- 1930: destaques da história gráfica no acervo da biblioteca nacional. Rio de Janeiro: Verso Brasil,2009

O início do design de livros no Brasil. In: 0 design brasileiro antes do design: aspectos da história gráfica, 1870 - 1960. São Paulo: Cosac Naify, 2005.

FLUSSER, Vilém. 0 mundo codificado: por uma filosofia do design e da comunicação. São Paulo: Cosac Naify, 2007.

GOULEMOT, Jean Marie. Da leitura como produção de sentidos. In: CHARTIER, Roger (dir). Práticas de leitura. São Paulo: Estação Liberdade, 1999.

HALLEWELL, Laurence. O livro no Brasil. São Paulo: Edusp, 2005.

MARCUSCHI, Luiz Antônio. Gêneros Textuais: definição e funcionalidade. In: DIONISIO, Angela; MACHADO, Anna; BEZERRA, Maria. (Org.). Gêneros Textuais \& Ensino. Rio de Janeiro: Editora Lucerna, 2003. p. 19-36.

SUDJIC, Deyan. A Linguagem das Coisas. Rio de Janeiro: Intríseca, 2010 